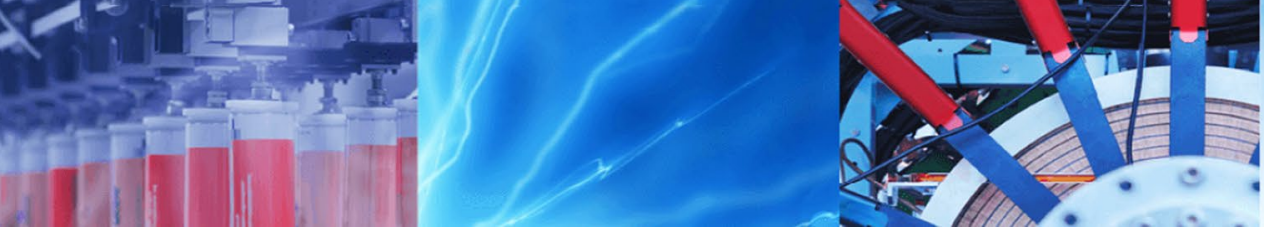

Research Article

\title{
Comparison on corrosion performance of waste-based multi-hybrid structure high carbon steel and high $\mathrm{Cr}$ cast steel
}

\author{
Wilson Handoko ${ }^{1}$ D $\cdot$ Farshid Pahlevani ${ }^{1} \cdot$ Veena Sahajwalla ${ }^{1}$
}

Received: 28 July 2020 / Accepted: 5 October 2020 / Published online: 7 October 2020

(c) Springer Nature Switzerland AG 2020

\begin{abstract}
Series of protective layer on high $C$ steel have been successfully developed through transforming various wastes. While high $\mathrm{Cr}$ cast steel (HCCS) offers excellent properties of toughness, hardness and corrosion resistance. In this research, the focus on characterisation methods of HCCS were conducted by SEM/EDS, TEM, XRD, Tafel and EIS curves. Results have revealed that modified surface high $C$ steel performed higher corrosion resistance than $16.0-16.5 \% \mathrm{Cr}$ steel. This finding has opened the new context of using wastes as a source for producing protective layer on the surface of high C steel that integrated profitability of steel products, thus, minimising production cost.
\end{abstract}

Keywords High C steel · Waste $\cdot$ Protective layer $\cdot$ High Cr cast steel $\cdot$ Corrosion

\section{Introduction}

In recent years, the demand of high $C$ steel has been substantially increased, due to its superior properties from combination of strength-hardness ratio $[1,2]$ and lowcost steel that is continuously used in aviation, chemical and mining industries $[3,4]$. With its mediocre level of corrosion resistance, it can inevitably lead to the loss of materials or failure on machineries and applications and should be further enhanced. Furthermore, in mining environment, water is very essential at almost every stage of its process and the main assets of the mining sites are located at water-stressed area, which has forced to find an alternative solution to resume the mining operation [5]. The used of sea water is one of the effective solutions, but with chloride content in the water that can increase the propensity towards corrosion attack of high $\mathrm{C}$ steel applications.

Recently, extensive researches have been devoted on resistance to corrosion by selecting and adding alloying element such as $\mathrm{Cr}$ in composition of steel. This method has been proven to be effective in significantly prevent corrosion degradation. For instance, the high Cr cast steels (HCCS) have been widely covered various sectors and industrial applications, due to its excellent properties of toughness, hardness, wear and corrosion resistance that suit to use in corrosive environment. Their superior properties result mainly from emergence of high-volume fraction hard $\mathrm{Cr}$-rich $\mathrm{M}_{7} \mathrm{C}_{3}$ carbides $[6,7]$. However, it has a major drawback, due to its high addition of alloying element, $\mathrm{Cr}$ (typically exceed $12 \mathrm{wt} \%$ ) content in steel $[8,9]$, which is typically expensive, the cost-efficient of this grade of steel is highly unlikely to be achieved. The microstructure contained different constituent phases that have direct influence on its chemical and mechanical properties. Transition metal carbides such as precipitation of $\mathrm{M}_{7} \mathrm{C}_{3}$ carbide in high $\mathrm{Cr}$ content steel, can dramatically affect its properties $[6,7]$. This includes the crystal orientation, transition metal carbide stability and its thermodynamic properties $[6,7]$. The carbides are commonly formed in HCCS that have few complicated crystal structures, and its chemical formulas usually correlate on $\mathrm{C}, \mathrm{Cr}$ and other alloy element concentrations [10]. Nevertheless, to achieve certain properties

Wilson Handoko, wilson.handoko@yahoo.com $\mid{ }^{1}$ Centre for Sustainable Materials Research and Technology (SMaRT Centre), School of Materials Science and Engineering, UNSW, Sydney, NSW 2052, Australia. 
that high $C$ steel can offers, it requires the use of energy, resource and time through adding complex heat treatment process, thus, corresponding to higher production cost. Note to mention that these attempts have limited success.

To achieve the desire properties that high $\mathrm{C}$ steel has offers, an economical solution can be implemented through used of different type of wastes to generate multihybrid layer on the surface of high $C$ steels to improve its corrosion resistance in single step-controlled heat treatment system at low temperature without altering bulk properties, which have been studied in recent research. Every year, millions of tonnes of wastes such as slag from steelmaking industry typically generated by electric arc furnace (EAF) [11], non-recyclable glass from laminated or tempered glasses and heterogenous mixture of plastics from automotive sector, especially automotive shredder residue (ASR) were discarded in the landfills. Disposed of these wastes has ignored the potential applications as value-added or supplementary materials, such as $\mathrm{Fe}, \mathrm{Si}, \mathrm{C}$, $\mathrm{Ti}[12,13]$, instead of using new resource excavated from the mining. The aim of this study is to overview and compare to what extend this generated multi-hybrid layer on high C steels, that able to compare with costly HCCS alloys in terms of corrosion resistance perspective.

\section{Experimental procedures}

\subsection{Materials preparation}

High $C$ steel with nominal composition of $1.1 \% \mathrm{C}$, $0.15 \% \mathrm{Mn}, 0.40 \% \mathrm{Si}, 0.65-0.70 \% \mathrm{Cr}, 0.02 \mathrm{Mo}$ and balance, units are in wt\%, was utilised in this investigation. Different multi-hybrid layer has been successfully bonded on the surface of high $C$ steel samples, derived from various wastes from the previous studies [14-16]. The evidence of the existence of multi-hybrid layer of the steels with different mixture of wastes approach and in-depth characterisations of the coatings were clearly described in these previous researches [14-16]. The corrosion resistance that HCCS alloys with similar composition with different Cr content $18.5-19.0 \% \mathrm{Cr}$ on sample-A and $16.0-16.5 \% \mathrm{Cr}$ on sample-B) have been used to overview and compared its corrosion resistance properties in $3.5 \% \mathrm{NaCl}$ solution condition. All steel samples were cut by Struers Accutom-50 at low speed rate to avoid heat transfer that can have direct impact on microstructure changes, grinded using SiC paper by Struers Tegramin-30, finely polished using diamond suspension and colloidal silica by Struers Rotopol-22, cleaned by ultrasonic cleaner, dried and stored into desiccator to minimise oxidation. The used of $2 \%$ nital solution to reveal the microstructures of high $\mathrm{Cr}$ steels.

\subsection{Analytical methods}

Optical microscope-Nikon ME-600 was adopted to observe and compare different microstructure characteristic on HCCS alloy samples. XRD analysis was conducted to provide quantitative data of presence of different phases in which were strongly presented in the steels, by using Empyrean (PANalytical) that equipped with HighScore Plus software. The Co-Ka radiation was chosen for this experiment to avoid strong florescence influence from $\mathrm{Cu}$ radiation and to receive high precision spectrum, at $45 \mathrm{kV}$ and $40 \mathrm{~mA}$ to measure different intensity in $2 \theta$ angle position between $20^{\circ}$ and $130^{\circ}$. High-resolution SEM images and EDS micro-analysis by JEOL-70001F to observe elemental composition of phase or presence of any secondary phase that can be considered on its effect to corrosion resistance. TEM-Phillips CM200 was used to observe presence of Mo and V carbides in the HCCS. A reliable corrosion rate measurement through Tafel polarisation technique-Versatile Multipotentiostat VSP-300 has been implemented to compare the overall corrosion rate between multi-hybrid layer steels and HCCS against the base-material high C steel. Three electrodes (saturated calomel electrode (SCE)—reference, platinum (Pt) electrode-auxiliary and steel samples-working). Open circuit potential (OCP) mode was used in the experiments, with $1 \mathrm{~cm}^{2}$ diameter as tested surface area of steels for $4 \mathrm{~h}$. Tafel plot was recorded between $-250 \mathrm{mV}$ and $+250 \mathrm{mV}$ with scan rate of $0.25 \mathrm{mV} / \mathrm{s}$. Therefore, corrosion potential, $E_{\text {corr }}$ and current density, $\mathrm{i}_{\text {corr }}$ can be defined. Electrochemical impedance spectroscopy (EIS) method was used with OPC mode at corrosion potential $10 \mathrm{mV}$, frequency range between $100 \mathrm{kHz}$ and $0.01 \mathrm{~Hz}$ with 24 hour time.

\section{Results and discussions}

\subsection{Optical microscopy}

In Fig. 1, it showed polarised light microscopy images of microstructures of HCCS at different magnification, in comparison with the previous study of multi-hybrid structure high carbon steel, sample HCS-C [14]. The dark colour represented martensite (M) phase, whereas ferrite (F) phase in bright colour. It can be observed that with higher $\mathrm{Cr}$ percentage, it refined both martensite and ferrite phases on sample-A over sample-B. Furthermore, $X$-ray spectrums in Fig. 2 suggested that in this microstructure, the presence of mostly eutectic chromium, Cr-rich $\left(M_{7} C_{3}\right)$ carbides dispersed in the martensite 

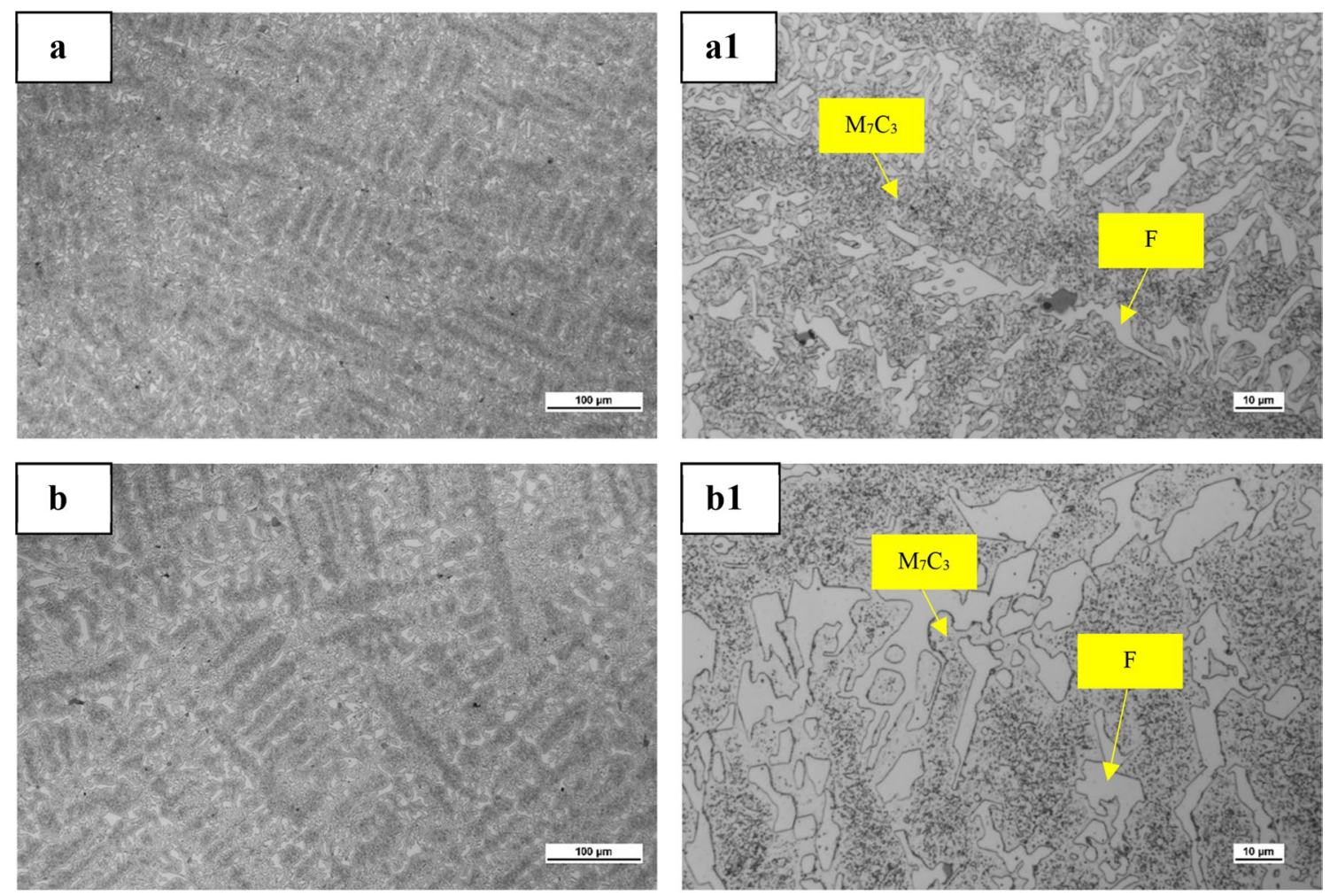

Fig. 1 Optical imaging of different high $\mathrm{Cr}$ content in steel on a sample-A and $\mathbf{b}$ sample-B with its different magnification on $\mathbf{a} 1$ and $\mathbf{b} \mathbf{1}$ respectively

Fig. 2 XRD diffraction spectra for HCCS alloys on a sample-A and $\mathbf{b}$ sample- $B$, where martensite $(\mathrm{M})$ and ferrite $(\mathrm{F})$

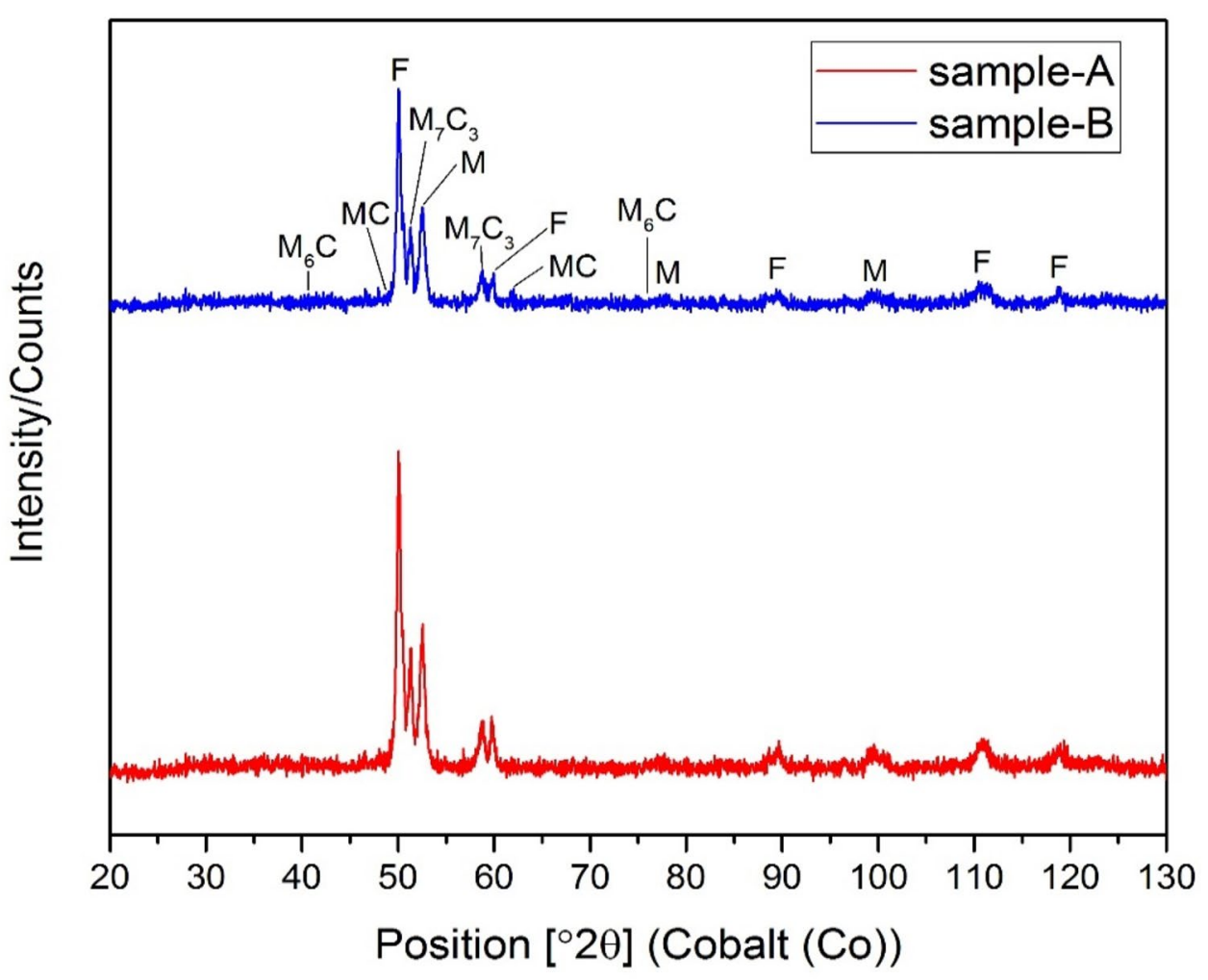

SN Applied Sciences

A SPRINGER NATURE journa 
phase matrix. The presence of less interconnected $\mathrm{M}_{7} \mathrm{C}_{3}$ carbides and ferrite promoted combination of abrasion resistance [17] and toughness [18] properties, respectively. With high alloying elements such as $\mathrm{Cr}$ in cast steel will significantly improve its corrosion resistance, thus, reduced the propensity of corrosive degradation, but it can be a costly steel product. Existence of molybdenum, Mo-rich $\left(\mathrm{M}_{6} \mathrm{C}\right)$ and vanadium, V-rich $(\mathrm{MC})$ carbides $[19,20]$ were detected in very low concentration of XRD spectrum in both steels, this can be due to very low amount of Mo and V elements in steels. However, further investigation on its micro-analysis through SEM/EDS analysis will be implemented to prove this assumption.

\subsection{SEM/EDS analysis}

The element distributions inhibited on each steel was better appreciated in SEM in back-scatter electron (BSE) mode and EDS mapping analysis in Fig. 3 for sample-A and sample-B. It can be clearly observed that grain boundary of martensite and ferrite phases have been performed through BSE, with $\mathrm{Cr}$-rich of $\mathrm{M}_{7} \mathrm{C}_{3}$ carbides in the martensitic phase on both HCCS. Additionally, it has been shown that Mo-rich and V-rich carbides were existed in very low concentration on the tested steels. These secondary phases can downgrade the corrosion resistance of steel as it will promote intergranular corrosion attack [21, 22] and can cause pit growth, but with low volume fraction of
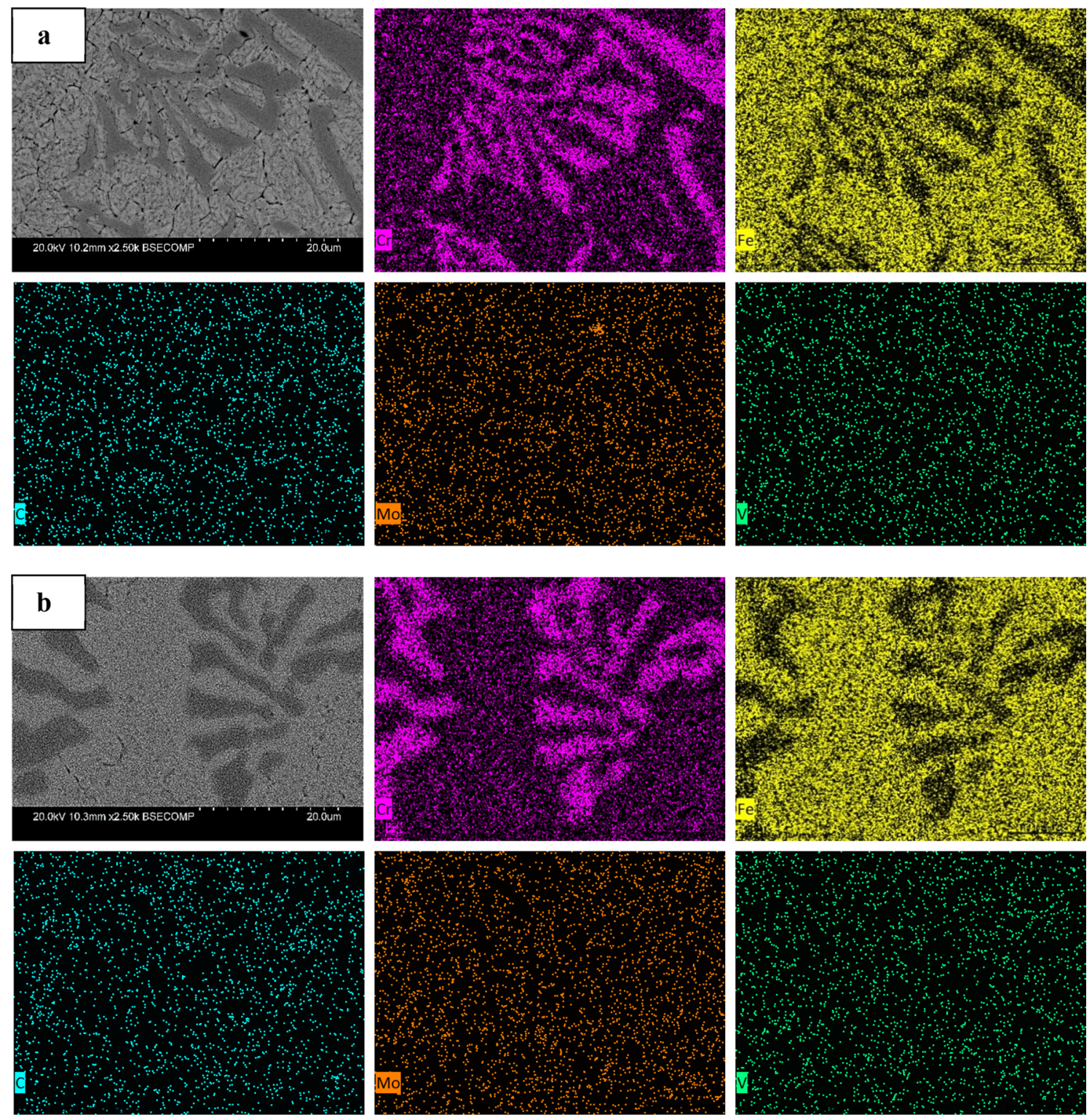

Fig. 3 SEM (BSE mode) images and EDS micro-analysis on Cr, Fe, C, Mo and V elements of HCCS alloys for a sample-A and $\mathbf{b}$ sample-B

\section{SN Applied Sciences}

a SPRINGER NATURE journal 
these inclusion, will not have significant impact on overall corrosion resistance. In this microstructural analysis, a slightly different in size of constituent phases can lead to direct impact on the corrosion resistance properties of steels.

A reference SEM and EDS analysis of the waste-based multi-hybrid structure high carbon steel is referred to the previous study [14]—sample HCS-C, where the multihybrid layer composed from chromium nitride (CrN), magnesium nitride $\left(\mathrm{Mg}_{3} \mathrm{~N}_{2}\right)$ and other metallic phases, such as $\mathrm{TiN}$ and $\mathrm{TiO}_{2}$, in comparison with the current results of HCCS alloys. In-depth analysis to observe the presence of Mo and V carbides in HCCS is presented in Fig. 4 below through the TEM analysis.

\subsection{Tafel polarisation methods}

Corrosion tests have been conducted through Tafel polarisation method to measure and compare its corrosion rate and calculated the percentage of protection efficiency, $\eta_{\mathrm{p}}$. The Tafel curves of multi-hybrid layer high $C$ steel and HCCS alloys against the base-material high $C$ steel is presented in Fig. 5. From this graph, the difference properties of corrosion resistance on tested steels were defined by low $\mathrm{i}_{\text {corr }}$ value and more positive $\mathrm{E}_{\text {corr }}$ value toward noble side. A summary of Tafel quantitative data is presented in Table 1. It can be observed that highest $\mathrm{Cr}$ cast steels-sample-A owned the highest corrosion resistance contributed to $64.43 \%$, followed by multi-hybrid layer steel about $51.98 \%$ and sample-B respectively around $36.89 \%$, lastly base-material of high $C$ steel as reference to calculation of $\eta_{p \cdot}$ A very significant improvement of both $i_{\text {corr }}$ and $\mathrm{E}_{\text {corr }}$ on multi-hybrid layer steel than base-material high $C$ steel and was closed to $18.5-19.0 \% \mathrm{Cr}$ cast steel-sampleA. On the other hand, sample-B performed higher $i_{\text {corr }}$ value and more negative $E_{\text {corr }}$ value than multi-hybrid layer steel, meaning that waste-integrated inputs as source for production of multi-hybrid layer steels has corrosion resistance behaviour somewhere between these HCCS alloys. Furthermore, in these dual-structure steels, preferential corrosion degradation on ferrite then followed by martensite, this was mainly due to the $C$ content is higher in martensitic phase that led to phase stability than Fe-rich ferrite phase $[23,24]$. Meaning that martensite performed
Fig. 4 TEM analysis on the presence of Mo-rich and V-rich carbides on the HCCS

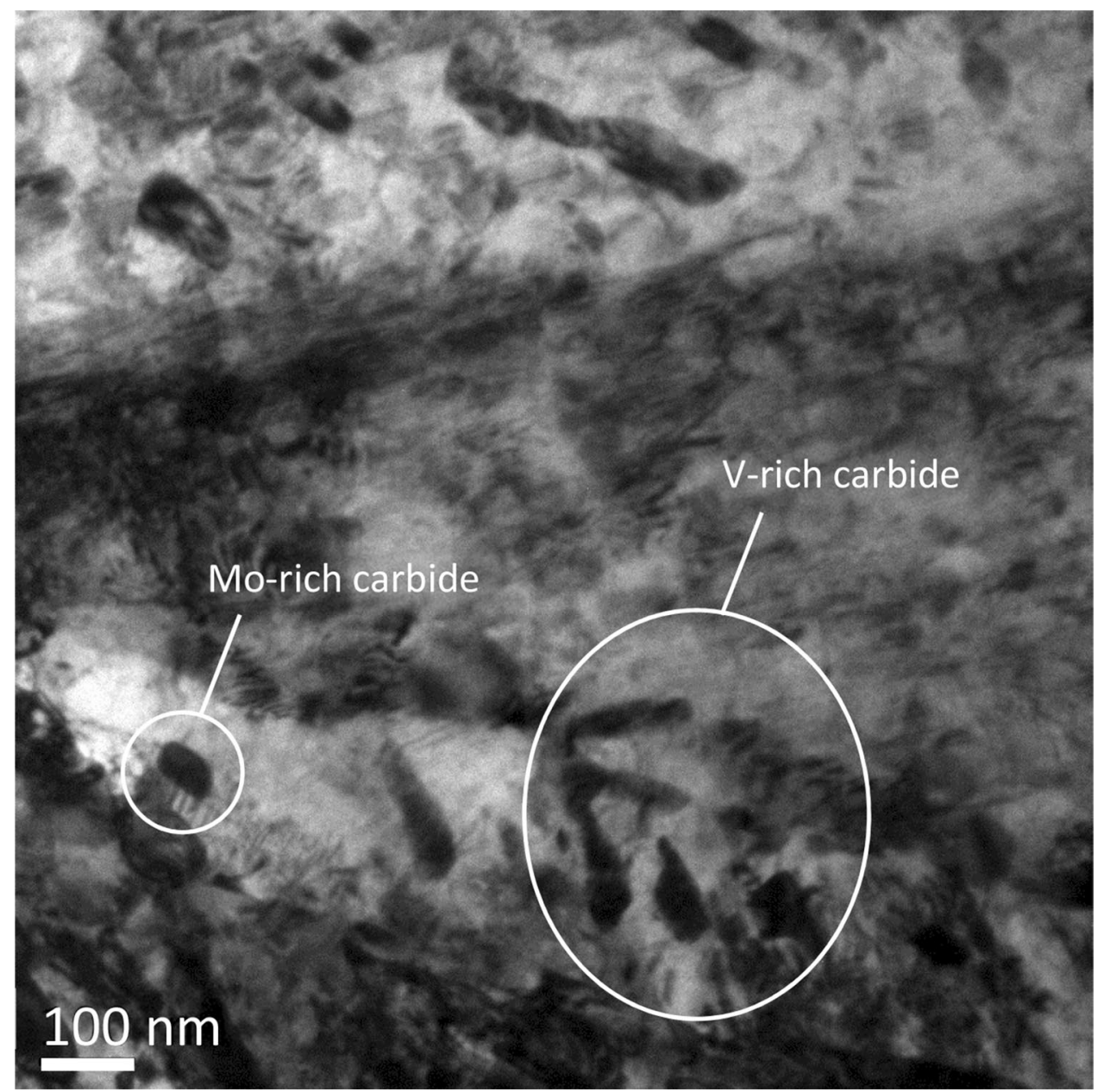

SN Applied Sciences A SPRINGer NATURE journal 
Fig. 5 The comparison of Tafel curves on base-material, different $\mathrm{Cr}$ percentage in cast steel-sample-A and sample-B and multi-hybrid layer high $C$ steel

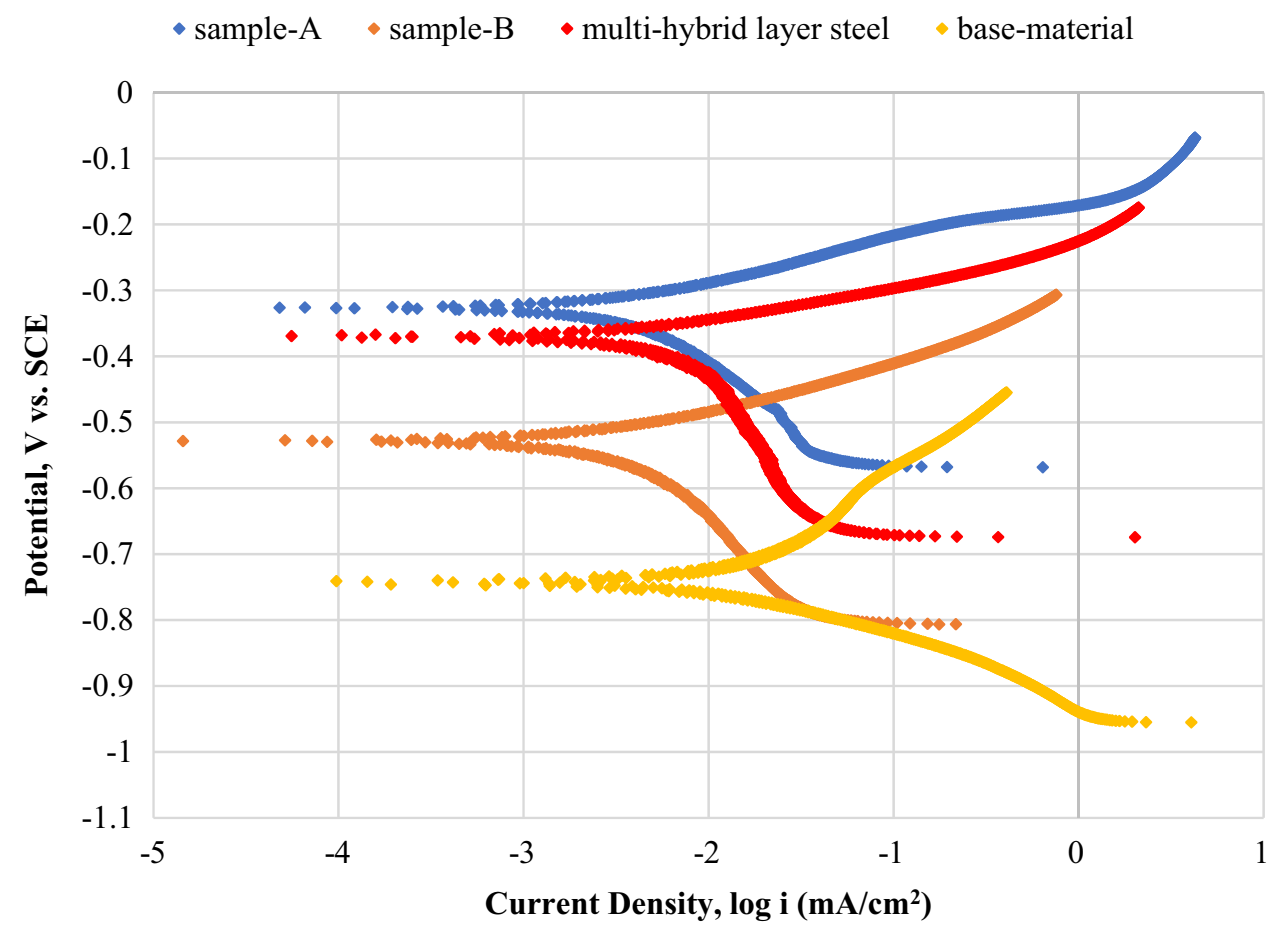

Table 1 Summary of Tafel parameters of multi-hybrid layer high C steel and HCCS against the base-material high $\mathrm{C}$ steel

\begin{tabular}{llll}
\hline Sample-ID & $\mathrm{E}_{\text {corr }}(\mathrm{mV}$ vs. SCE $)$ & $\mathrm{i}_{\text {corr }}\left(\mathrm{mA} / \mathrm{cm}^{2}\right)$ & $\eta_{\mathrm{P}}(\%)$ \\
\hline fBase-material high C & -742 & 0.0158 & - \\
$\quad$ Steel & & & \\
Sample-A & -326 & 0.00562 & 64.43 \\
Sample-B & -529 & 0.00997 & 36.89 \\
Multi-hybrid layer steel & -369 & 0.00759 & 51.98 \\
\hline
\end{tabular}

cathodic behaviour and ferrite exhibited anodic behaviour $[24,25]$. Other factor that can influence this preferential degradation on one phase than another, was because of iron atoms dissolutions. With controlled heat treatment process, the bulk properties remained unalter to maintain its original properties for multi-hybrid layer steel.

Corrosion mechanism of these steels were grain boundary corrosion [26], pitting corrosion [27] and intergranular corrosion [28]. Grain boundary corrosion was mainly due to the dual-structure of constituent phasesmartensite and ferrite that have difference in potential energy between contacted surface area or interface of both phases [26]. Additionally, it can be caused by different size, shape, distribution and stability of each phase in the steel that determined the overall corrosion degradation. Pitting corrosion or well-known as localised corrosion because of the depassivation of certain area on the surface of steels that caused anodic and cathodic half reaction to occur, promoting electromigration of aggressive anions and potential gradient that formed pit holes with limited numbers of diffusion of ions [27]. Intergranular corrosion was caused by deterioration along the grain boundaries due to thermodynamic effect for corrosion is higher at grain boundaries than at the inner grain boundaries in which exposure of certain crystalline on materials, impurity or secondary phase and difference in composition at a particular environment (electrochemical or chemical) that can initiate this type of corrosion $[28,29]$. Therefore, it can be concluded that corrosion resistance of high $C$ steel has been enhanced through multi-hybrid layer that able to match with costly HCCS.

Further analysis was performed by utilising the electrochemical impedance spectroscopy (EIS) method to confirm the finding in the Tafel polarisation curves above. EIS method has proven to be an effective tool to analyse the corrosion process of steels in different conditions. In Fig. 6, the Nyquist curve is presented, with higher corrosion resistance property, the size of the high-frequency (HF) loop is expanded, and the disappearance of inductive loop occurred. The increasing in diameter of the capacitive loop has proven to be reduced in the charge-transfer resistance and corrosion current density value. Therefore, the corrosion resistance property of the sample-A is the highest, followed by multi-hybrid layer steel, sample-B and base material high C steel. 


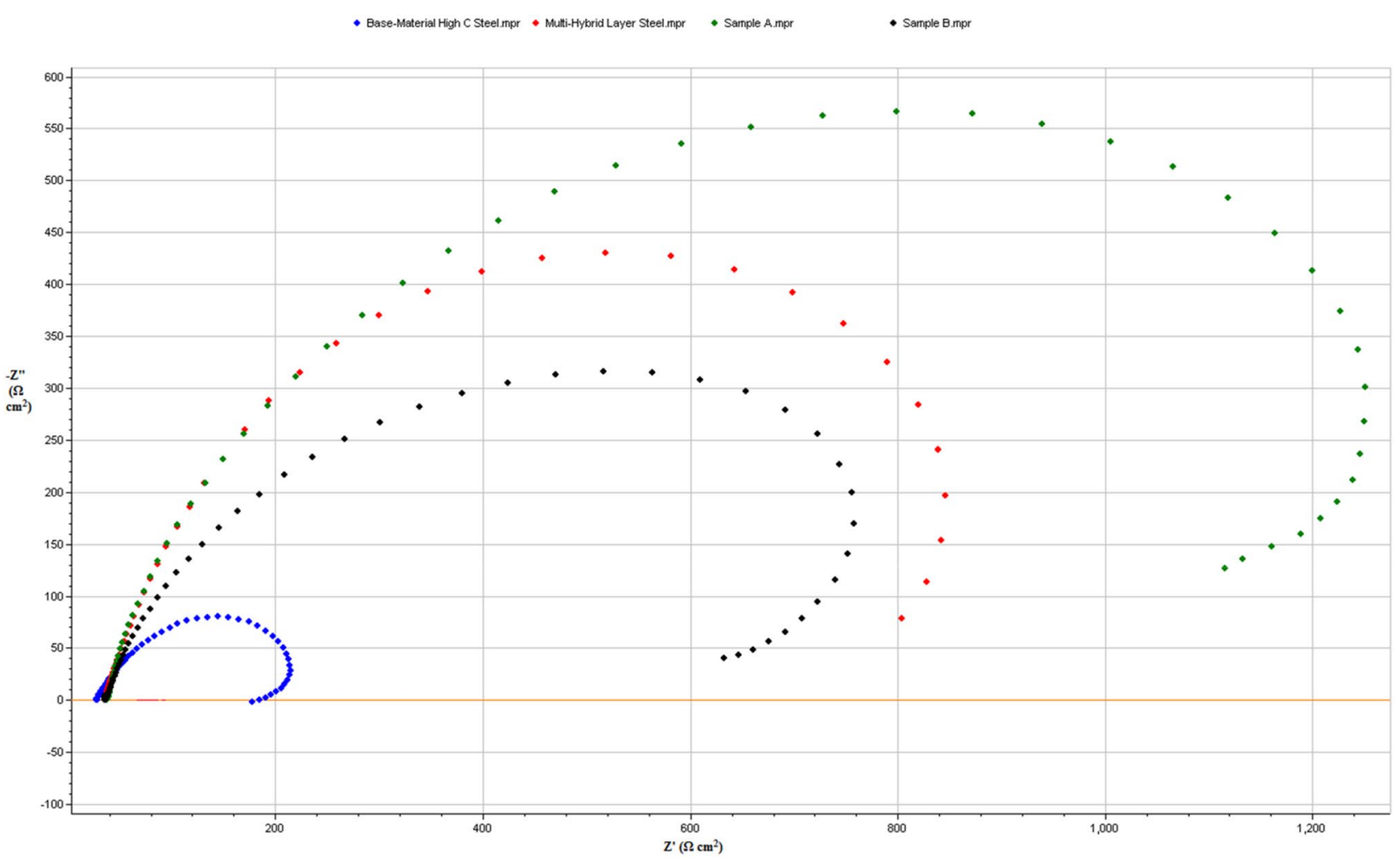

Fig. 6 The Nyquist curve from the EIS experimental data for base-material high C steel, multi-hybrid layer steel and HCCS samples

\section{Conclusions}

Corrosion resistance of low-cost high $\mathrm{C}$ steel has been improved through the production of multi-hybrid layer derived from various wastes-slag, non-recyclable glass and heterogenous mixture of plastics from ASR, via heat treatment. Microstructural and crystallography analysis by polarised light microscopy, SEM/EDS and XRD have proved the presence of eutectic $\mathrm{Cr}$-rich, $\mathrm{M}_{7} \mathrm{C}_{3}$ carbide in the martensite matrix on both HCCS. The presence of Mo-rich $\left(\mathrm{M}_{6} \mathrm{C}\right)$ and vanadium, V-rich $(\mathrm{MC})$ carbides were detected using a TEM analysis. Although HCCS can significantly enhance corrosion resistance properties with good combination of toughness, hardness and wear resistance, but they are not cost-efficient. Results have revealed that this type of multi-hybrid layer steel was able to compete with $18.5-19.0 \% \mathrm{Cr}$ cast steel, which contributed to 51.98 and $64.43 \%$ improvement in corrosion resistance properties respectively than in base-material high C steel. This study has opened a new opportunity to utilised wastes as source for production of protective layer of low-cost high C steel to save production cost, reducing the dependency on new resources and minimising the impact to the environment through disposed of wastes into landfills.
Acknowledgements This research was supported under Australian Government Research Training Program (RTP) and Australian Research Council's Industrial Transformation Research Hub funding scheme (project IH130200025). We gratefully acknowledge the technical support provided by UNSW Mark Wainwright Analytical Centre-Electron Microscope Unit in UNSW Sydney.

Author contributions WH designed and performed experiments and data analysis. FP performed experiments and critically analysed the data. VS supervised the study and gave recommendations to revise manuscript. WH wrote the manuscript and all authors analysed data, discussed the results, read and approved the final manuscript.

Data availability The data that support the findings of this study are available from the corresponding author upon reasonable request

\section{Compliance with ethical standards}

Conflicts of interest The authors declare no conflicts of interest.

\section{References}

1. Tao Q, Wang J, Fu L, Chen Z, Shen C, Zhang D, Sun Z (2017) Ultrahigh hardness of carbon steel surface realized by novel solid carburizing with rapid diffusion of carbon nanostructures. J Mater SciTechnol 33(10):1210-1218 
2. Schaupp T, Schroepfer D, Kromm A, Kannengiesser T (2017) Welding residual stresses in $960 \mathrm{MPa}$ grade QT and TMCP highstrength steels. J Manuf Processes 27:226-232

3. Qin S, Liu Y, Hao Q, Wang Y, Chen N, Zuo X, Rong Y (2016) High carbon microalloyed martensitic steel with ultrahigh strengthductility. Mater SciEng A 663:151-156

4. Hui W, Zhang H, Zhang Y, Zhao X, Shao C (2016) Effect of nickel on hydrogen embrittlementbehavior of medium-carbon high strength steels. Mater SciEng A 674:615-625

5. Beale R, Airs R (2016) Quantification of glycine betaine, choline and trimethylamine $\mathrm{N}$-oxide in seawater particulates: minimisation of seawater associated ion suppression. AnalyticaChimicaActa 938:114-122

6. Yan F, Shi H, Fan J, Xu Z (2008) An investigation of secondary carbides in the spray-formed high alloyed Vanadis 4 steel during tempering. Mater Charact 59(7):883-889

7. Ma S, Xing J, He Y, Li Y, Huang Z, Liu G, Geng Q (2015) Microstructure and crystallography of $\mathrm{M} 7 \mathrm{C} 3$ carbide in chromium cast iron. Mater ChemPhys 161:65-73

8. Zhao J, Zhao T, Hou C, Zhang F, Wang T (2015) Improving impact toughness of high-C-Cr bearing steel by $\mathrm{Si}-\mathrm{Mo}$ alloying and low-temperature austempering. Mater Des 86:215-220

9. Lee K, Suh J, Hong S, Huh J, Jung W (2015) Microstructural evolution and creep-rupture life estimation of high-Cr martensitic heat-resistant steels. Mater Charact 106:266-272

10. Adegoloye G, Beaucour A, Ortola S, Noumowé A (2015) Concretes made of EAF slag and AOD slag aggregates from stainless steel process: mechanical properties and durability. Constr Build Mater 76:313-321

11. Svensson L, Gretoft B, Ulander B, Bhadeshia H (1986) Fe-Cr-C hardfacing alloys for high-temperature applications. J Mater Sci 21(3):1015-1019

12. PahlevaniHeriyanto F, Sahajwalla V (2018) Waste glass powder innovative value-adding resource for hybrid wood-based products. J Clean Prod 195:215-225

13. Handoko W, Pahlevani F, Emmanuelawati I, Sahajwalla V (2016) Transforming automotive waste into TiN and TiC ceramics. Mater Lett 176:17-20

14. Handoko W, Pahlevani F, Sahajwalla V (2019) Enhancing corrosion resistance of high-carbon steel by formation of surface layers using wastes as input. Metals 9(8):902

15. Handoko W, Pahlevani F, Yao Y, Privat K, Sahajwalla V (2019) From waste to multi-hybrid layering of high carbon steel to improve corrosion resistance: an in-depth analysis using epma and afm techniques. Surfaces 2(3):485-496

16. Kan W, Huang S, Man Z, Handoko W, Chang L, Pahlevani F, Rasmussen K, Sahajwalla V (2020) Utilization of waste materials for the manufacturing of better-quality wear and corrosion-resistant steels. Metall Mater Trans A 51(5):2404-2410
17. Zhao C, Zhou Y, Xing X, Liu S, Ren X, Yang Q (2018) Investigation on the relationship between $\mathrm{NbC}$ and wear-resistance of Fe matrix composite coatings with different $\mathrm{C}$ contents. Appl Surf Sci 439:468-474

18. Zou Y, Xu Y, Hu Z, Chen S, Han D, Misra R, Wang G (2017) High strength-toughness combination of a low-carbon mediummanganese steel plate with laminated microstructure and retained austenite. Mater SciEng A 707:270-279

19. Garza-Montes-de-Oca N, Ramírez-Ramírez J, Alvarez-Elcoro I, Rainforth W, Colás R (2013) Oxide Structures Formed During the High Temperature Oxidation of Hot Mill Work Rolls. Oxid Met 80(1-2):191-203

20. Kim H, Kang J, Son D, Lee T, Cho K (2015) Evolution of carbides in cold-work tool steels. Mater Charact 107:376-385

21. Sushko M, Schreiber D, Rosso K, Bruemmer S (2018) Role of $\mathrm{Cr}$ rich carbide precipitates in the intergranular oxidation of $\mathrm{Ni}-\mathrm{Cr}$ alloys. ScriptaMaterialia 156:51-54

22. Fujii T, Tohgo K, Mori Y, Shimamura Y (2018) Crystallography of intergranular corrosion in sensitized austenitic stainless steel. Mater Charact 144:219-226

23. Handoko W, Pahlevani F, Sahajwalla V (2018) The effect of lowquantity $\mathrm{cr}$ addition on the corrosion behaviour of dual-phase high carbon steel. Metals 8(4):199

24. Handoko W, Pahlevani F, Sahajwalla V (2018) Enhancing corrosion resistance and hardness properties of carbon steel through modification of microstructure. Materials 11(12):2404

25. Handoko W, Pahlevani F, Sahajwalla V (2017) Corrosion behaviour of dual-phase high carbon steel-microstructure influence. J Manufact Mater Process 1(2):21

26. Jinlong L, Tongxiang L, Chen W, Limin D (2016) Effect of ultrafine grain on tensile behaviour and corrosion resistance of the duplex stainless steel. Mater SciEng: C 62:558-563

27. Park I, Lee S, Kang M, Lee S, Lee $Y$ (2015) Pitting corrosion behavior in advanced high strength steels. J Alloys Compd 619:205-210

28. Handoko W, Pahlevani F, Sahajwalla V (2019) Stress-induced phase transformation and its correlation with corrosion properties of dual-phase high carbon steel. J Manufact Mater Process 3(3):55

29. La Fontaine A, Yen H, Trimby P, Moody S, Miller S, Chensee M, Ringer S, Cairney J (2014) Martensitic transformation in an intergranular corrosion area of austenitic stainless steel during thermal cycling. CorrosSci 85:1-6

Publisher's Note Springer Nature remains neutral with regard to jurisdictional claims in published maps and institutional affiliations. 